leukæmia in patients treated with radioactive iodine for cancer of the thyroid, when compared with the incidence of the disease in the healthy population at large, suggests that leukæmia may have to be regarded. as a calculated risk (even if only a small one) when this treatment is used for thyroid cancer. Pochin, however, suggested that when smaller dosages are given for the treatment of thyrotoxicosis, the present known incidence of leukæmia does not appear to be greater than that which could have been said to have arisen by chance. Nevertheless, it is clearly desirable to watch this situation carefully and to extend observation over a longer period.

Ackerman et al. reported a simple and accurate test for the diagnosis of thyroid cancer. This consists of giving orally $500 \mathrm{mc}$. of phosphorus-32. 'Twentyfour hours later, multiple counts are taken of the radioactivity from suspicious nodules. In six cases uptake of phosphorus-32 was increased markedly. These were afterwards shown to be malignant tumours. It was very interesting to find that one case of Hashimoto's disease also suggested malignancy by this test. Thirty-four negative tests were produced and in all those operated upon (22), except one, benign tumours were diagnosed.

It is twenty-two years since the last International Goitre Conference, and although striking advances in both knowledge and technique have occurred during this time, it will be apparent that many fundamental problems still remain unresolved.

The lato Edwin Ramsdell had prepared an address which was read at the opening of the conference. In it he reminded the members that at the third conference there had been no mention even of antithyroid drugs, let alone of radioactive isotopes. How completely the position has changed will be evident from the wide compass of topies dealt with in 1960 .

C. Rimington

R. A. Miley

${ }^{1}$ Astwood, E. B., et al., J. Biol. Chem., 181, 121 (1949).

${ }^{2}$ Bachelard, H. S., and Trikojus, V. M., Nature, 185, 80 (1960).

Glock, G. E., Nature, 154, 460 (1944).

\title{
THE BRITISH COMPUTER SOCIETY
}

\section{HARROGATE MEETING}

COME 400 delegates attended the second annual $S$ conference of the British Computer Society, held at Harrogate during July 4-7. The president, Dr. M. V. Wilkes, noted with satisfaction that the Society, with one annual meeting behind it, was indeed flourishing.

In his opening address, Dr. Wilkes announced the formation of an International Federation of Information Processing Societies, in which the British Computer Society would represent the United Kingdom. The Federation has elected its secretary-treasurer (A. Speiser, Switzerland), president (I. Auerbach, United States) and vice-president (A. Walther, Germany), and has announced that its next conference will be in Munich in September 1962.

Dr. Wilkes referred to the activities of the publication committees of the British Computer Society, and especially to the technical committees on automatic programming. He thought that scientific auto-coding was now generally accepted, but that the break-through in auto-code language for commercial applications, the results of which could be devastating, was still to come. One of the most important eurrent problems was that of datatransmission, and he compared the rather slow teleprinter circuit, with difficult checking facilities, with the telephone circuit with forward errordetecting codes and automatic repeat when necessary. An interesting point was that 100 per cent accuracy is not essential, the aim being to make the transmission of information as accurate as any further processing thereof. $\mathrm{He}$ envisaged the less-pecunious universities ringing round to their more fortunate brethren, sending their problems by telephone to the fastest and cheapest service. Again, however, he warned that the solution of the problem, though imminent, was not yet effected.

The second session discussed a common computer language. C. Strachey (formerly of the National Research Development Corporation) outlined the problems arising in the construction of such language and its advantages to programmers, and mentioned important advances made by the United States in the technique of 'list processing'. He made a plea for humans to regard their time as valuable, and to refrain from relapsing into slavery to the machine. R. Brooker (University of Manchester) spoke in technical terms of some recent work in constructing translating routines, carried out at Manchester, for any 'computer-oriented' language. and reported success with regard to the autocodes of Pegasus and Mercury. These methods apparently need a machine with a fairly large store, though $\mathrm{K}$. Tocher (United Steel) reported success in devising restricted autocodes for smaller machines.

Business applications also have their auto language, and R. Paine (I.C.T.) outlined the desirable features of such a language and some attempts made to meet them. He warned that management cannot yet dispense with its programming staff, that the language of the accountant is not yet that of the computing machine, and envisaged the evolution of long-hand and short-hand versions of the language. This contribution included the comments that a computer conference might be described as a "meeting of contiguous word-noises", and that machine manufacturers' advertisements of business computer auto. codes rarely err on the side of modesty.

At about this stage one notes with sorrow the transformation of certain features of the English language, and too often its mutilation which, in these vulgar times, seems to accompany the development of any new scientific field, and in which computer terminology is second to none. One finally applauded the question, "What exactly, please, is a programmer ?", and listened with regretful admiration to the chairman's "Since it is now time for coffee, I shall have to treat that question as rhetorical !"

The next session was also concerned with language and general-purpose programmes, this time for market research (A. Douglas, University of Leeds, and R. Cook, Elliott Bros.), which provided facilities 
for receiving and verifying data, forming frequency tables, and printing results in any desired format, and in general statistical survey work (F. Yates, Rothamsted), and success was reported with several of the smaller machines.

Small computers were also featured in a symposium on their use in a variety of problems covering clerical processes, production-control in a medium-sized factory, an analysis of a reasonably complicated hydro-electric system, and stock control in a shoe factory. This sequence of thoughtful, well-presented papers seemed to leave the audience rather bemused. Did they, one wonders, ponder on the remarkable advanees in the past docade when machinos like the Stantec Zebra, ICT 1201, Elliott 402 and 802 and Ramac 305 can now properly be described as small, or wore they shattcred with the perfect simplicity of a data-transmission system in which a gamckcoper reads water-levels once a week, cycles ten miles, and sends off postcards?

S. Clarke (Elliott Bros.) and S. Gill (Forranti) gavo accounts of recent respective visits to the U.S.S.R. and the United States. Clarke reported great Russian interest in British computing equipment and their own assessment of a four years lag behind the West. He deseribed some Russian machines, none of which has a rapid access store of more than about 2,000 words, and noted that their present main interests wero in automation and language translation. $\mathrm{He}$ found little effort in general data-processing and commereial applications other than in pay-roll work. The Chinese have apparently made a perfect copy of one of the largest Russian machines in one year, indicating perhaps the shape of things to come.

( Till found advances in the United States rather disappointing in actual machines, and thought that new British projects such as the Atlas have no clear trans-Atlantic superior. In programming techniques parallel operation and time-sharing are all the rage, but enthusiasm for international machine languages liko Algol (scientific) and Cobol (commercial) are somewhat on the wane. For example, no Algol compiler is yet working efficiently for any machine in the United States, and university research is concentrated on more general studies in the theory of computer programming. He commented on the work of Hao Wang, an Oxford mathematical logician at present in America, who on an International Business Machines computer proved 350 significant theorems in "Principia Mathematica" in $8 \frac{1}{2} \mathrm{~min}$., exclusive of printing timo. Wang has remarked on the great significance for mathematics of the cross-fertilization of 'inferential calculus' and computing machines. Here is certainly a fuscinating ficld of research, neoding for its success mathematicians of the highest competence and machines of a size greater than any at present installed in a British university.

Attention was directed in one of the sessions to the organization of computing centres in universities (R. Buckingham, University of London) and industrial establishments (A. Bagshaw, Fcrranti). University work covers a very broad field, mainly scientific, with consequent advantages for the 'open shop' method of working, in which most users write, test, and perhaps run their own problems. This, of course, is not always possible; the 'unfluppability' of the Chancellor of the University of Oxford would, one imagines, be tested severely, and unfairly, by his first fow attempts at prograrnme ehecking. Commercial centres have similar problems except that scientific work is beginning to be swamped by general data-processing calculations, with consequent greatcr economy in more operator-controlled machine running. This tendency will intensify when 'timesharing' machines come into general use. A. Bcaven (National Computer Research) had a different problem of organization, involved in the training of operators and the writing of programmes to check and correct data, derived from automatic paper-tape punches attached to accounting machines, for input to a computer, such data amounting to nearly threequarters of a million paper-tape characters a month.

Time-sharing was put into practice when the numerical analysts, in surprisingly large numbers, discussed some new techniques for applying predictorcorrector formulæ in initial-value problems and for the iterative solution of non-linear boundary-value problems in ordinary difforential equations, the determination of latent roots of matrixes when the parameter appears in non-linear form, and the behaviour of the remainder term and other aspects of Gauss-type quadrature formulie. These papers comprised a small but fairly representative sample of curront research in 'computer-oriented' numerical analysis. At the same time, the larger group studicd problems of simulation in ehemical plants, power stations and othor works, the computer being used to make adjustments to the detailed procoss, using a 'mathematical model' and a statement of objectives, in order to incroase efficiency and output.

On the last morning, D. Polley (Ministry of Pensions and National Insurance) and Col. L. Slater (Royal Army Pay Corps) gave accounts of respective progress in the installation of data-processing schomes for insurance records and for the payment of the military. In both cases the machinery required seemed to be substantial, with reels of magnetic tape and a 'Xeronic' printer on one hand, to cope with the processing, in a six-monthly period of each year, of thirty million tax-reduction cards, and on the other an International Business Machine 705 computer, 1,401 tabulation systom and a staff of 100. Soldiers must have their pay, and one sympathizes with the problem of maintaining continuity in reimbursement and record in the process of changing from manual to automatic operation.

Finally, a small symposium (which might well have shared time with numerical analysis so that oll, including myself, could have heard about simulation) discussed techniques of accounting, in wholesale and retail branch control, in 'invoicing' in general, in the paper industry in particular, and in banking. Here, it seems, the problems of programming are trivial compared with those of deciding the factors which should be taken into account (as, for exarnple, the loss of weight in stored cheese), and of collecting all the parts into a coherent logical entity.

The organization of the meeting was good and its after-effects promising, since those who could not attend will apparently have a chanco to study at more leisure at least some of the main contributions, which will be published in the Computer Journal. We lacked only sunshine (perhaps mercifully in the Harrogate Sun Pavilion) and, as usual, time for adequato discussion. The Pavilion was just large enough to accommodate the full audienee and reception and entertainment, provided by the Mayor, and a small exhibition of computing mechanisms, models and plans, provided by the leading British manufacturers, in an atmosphere at once both sufficiently formal and intimate. 